\title{
Room-temperature adsorption behavior of cesium onto calcium silicate insulation
}

\author{
Muhammad RIZAAL*, Takumi SAITO**, Koji OKAMOTO**, Nejdet ERKAN*, \\ Kunihisa NAKAJIMA*** and Masahiko OSAKA*** \\ *Department of Nuclear Engineering and Management, The University of Tokyo \\ 7-3-1 Hongo, Bunkyo-ku, Tokyo 113-8656, Japan \\ E-mail: rizaal@vis.t.u-tokyo.ac.jp \\ **Nuclear Professional School, The University of Tokyo \\ 2-22 Shirane, Shirakata, Tokai-mura, Naka-gun, Ibaraki 319-1188, Japan \\ ***Nuclear Science and Engineering Center, Japan Atomic Energy Agency \\ 2-4 Shirane, Shirakata, Tokai-mura, Naka-gun, Ibaraki 319-1195, Japan
}

Received: 31 October 2019; Revised: 5 January 2020; Accepted: 23 January 2020

\begin{abstract}
A calcium silicate insulator material was investigated for its interaction with non-radioactive cesium at room temperature by batch-type adsorption experiments. An industrial-grade calcium silicate was weighted and ground into powder with an average size of $15.4 \pm 0.1 \mu \mathrm{m}$, which was then placed into the polypropylene (PP) tubes containing cesium chloride aqueous solution. Cesium concentrations were range between $1.3 \times 10^{-6}$ $3.5 \times 10^{-3} \mathrm{M}$. Adsorption kinetics of cesium was evaluated based on pseudo-first order and pseudo-second order models, while the adsorption isotherm was modeled using the Langmuir model and modified BET model. Physicochemical properties of calcium silicate before and after the adsorption was investigated using XRD, SEM/EDS, and FT-IR. Chemisorption was found as the underlying sorption process between calcium silicate insulator material and cesium.
\end{abstract}

Keywords: Room-temperature adsorption, Calcium silicate insulation, Cesium, Chemisorption

\section{Introduction}

In January-February 2017, the series of internal investigations of the primary containment vessel (PCV) of Fukushima Daiichi nuclear power station unit 2 was performed by Tokyo Electric Power Company Holdings, Inc. (TEPCO). The main task of the investigation was to inspect the conditions of the platform inside the PCV, the fallen fuel debris to the control rod drive (CRD), and the pedestal internal structure (TEPCO, 2017a). The recording device managed to record the information of temperature, dose rate, and conditions of structures in the vicinity of the pedestal. The recorded dose rate in this report arose particular attention. The pedestal area, in regard to the accident progression, should exhibit a higher dose rate than those of other locations in its vicinity, as the location was most affected by molten fuels. In fact, the dose rates were $10 \mathrm{~Gy} / \mathrm{h}$ at the pedestal and $70-80 \mathrm{~Gy} / \mathrm{h}$ at its vicinity, as illustrated in Fig. 1 . At the same location, many deposits in the form of black pastes and thin gravel-size materials were found adhered to the surface, which were presumed as one of the causes for such a high dose rate. To date of the recent report (TEPCO, 2017b), it remains unsolved how these deposits were created. Based on the condition and location where these deposits existed, it is likely that the formation of such deposits was originated by steam containing fission products such as cesium, leaked from, e.g., safety relief valves component. We further presume that the leaked steam directly hit the thermal insulation of main steam piping, following that the adsorption of cesium on the insulator occurred.

Calcium silicate insulation material is a common insulator material used in piping systems for high-temperature purposes (Zheng et al., 2000; Leite et al., 2017). In the unit 2 of Fukushima Daiichi nuclear power station primary piping systems, this type of calcium silicate insulation was utilized (NISA, 2006). 


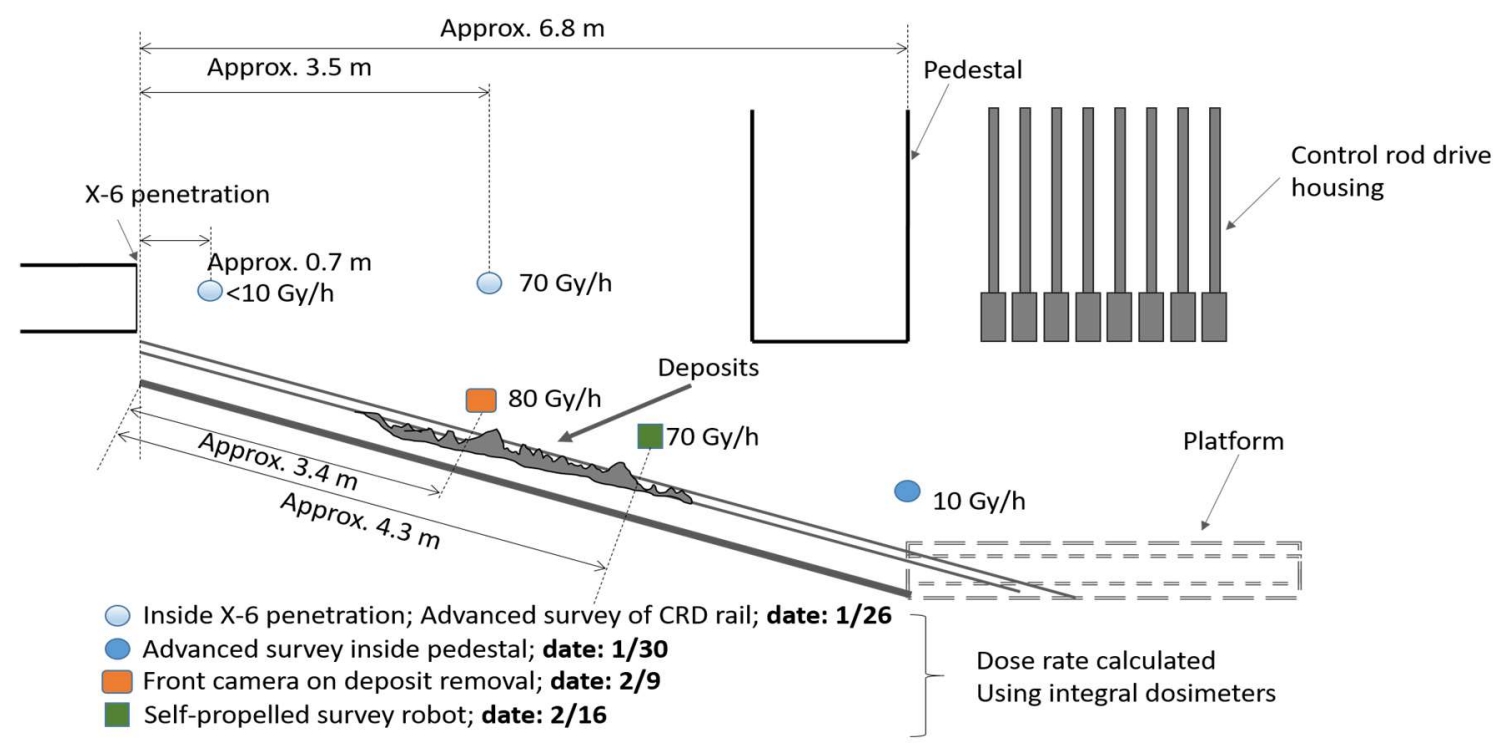

Fig. 1 High dose rate condition at the pedestal vicinity of Fukushima Daiichi NPS unit 2

The sorption of radionuclides to other forms or type of calcium silicate material have been investigated in some studies for immobilization strategies (Schlegel et al., 2004; Tits et al., 2006; Gaona et al., 2011; Tits et al., 2014; Steve et al., 2018). By far, a material used in the only one study by Hassan et al (2018) had close similarity to calcium silicate insulation. In their study, the sorption behavior of cesium and europium onto nano-sized calcium silicate (i.e. wollastonite) was investigated. Nevertheless, it is still inapplicable to extend the study to the Fukushima Daiichi case since the insulator material likely consists of different mineral phases of calcium silicate, xonotlite and tobermorite. Moreover, with regard to a severe accident, most researches were intensively centered on cesium adsorption on structural material such as stainless steel (Chang et al., 1992; Haste et al., 2013; Kalilainen et al., 2014; Di lemma et al., 2016). Therefore, as an initial effort to study cesium adsorption on calcium silicate insulation, the room-temperature adsorption study is conducted to construct fundamental information on the interaction of a calcium silicate insulator material and cesium.

\section{Materials and methods}

\subsection{Materials}

For all experiments, Milli-Q grade pure water and analytical-grade chemicals from Wako Pure Chemical Industries were used, unless otherwise noted. Cesium chloride $(\mathrm{CsCl})$ was used in this study. Calcium silicate insulation block, with specified insulation grade of the nuclear primary coolant system, was used as an adsorbent. Prior to the experiments, calcium silicate insulation block was cut into small pieces and then ground by an agate mortar.

\subsection{Characterization}

The particle size of the ground calcium silicate insulator material was measured using a laser diffraction size analyzer (SALD-2300, Shimadzu). A field emission scanning electron microscopy equipped with energy dispersive X-ray spectrometry (SEM/EDS, JSM-7610F, JEOL) was used to characterize the morphology and elemental distributions of the samples. A double-sided carbon tape was placed on a sample holder to place the samples and without any further coating. The secondary electron images were obtained at an applied voltage of $15 \mathrm{kV}$. The X-ray diffraction (XRD) analyses were performed using Rigaku MiniFlex $600\left(\mathrm{Cu}-\mathrm{K} \alpha\right.$ radiation) which the scan range was $2 \theta=10-80^{\circ}$ under continuous mode in a scan speed of $1 \% \mathrm{~min}$ and step of $0.01^{\circ}$. The applied current and voltage were $15 \mathrm{~mA}$ and $40 \mathrm{kV}$, respectively. The functional group of the material was analyzed with Fourier transform infrared spectroscopy (FTIR, Shimadzu FTIR-8400) by the KBr pellet method. 


\subsection{Adsorption Studies}

The cesium stock solution was prepared by dissolving $\mathrm{CsCl}$ with deionized water. Batch adsorption experiments were performed at $25^{\circ} \mathrm{C}$ using $50 \mathrm{~mL}$ conical polypropylene tubes placed inside a thermostat mechanical shaker. The particle size of ground calcium silicate was measured using a laser diffraction size analyzer (SALD-2300, Shimadzu) as $15.5 \pm 0.1 \mu \mathrm{m}$. For the purpose of adsorption kinetics, $0.02 \mathrm{~g}$ and $0.10 \mathrm{~g}$ of ground calcium silicate were mixed with $20 \mathrm{~mL}$ cesium chloride solution with different initial concentrations of $1.01 \times 10^{-5}$ and $1.01 \times 10^{-4} \mathrm{M}$, with contact time varied from 0.5 to 98 hours. The $\mathrm{pH}$ values of solutions were adjusted between 9.91 and 10.06 by adding $0.1 \mathrm{M} \mathrm{HCl}$ or $\mathrm{NaOH}$. Two adsorption isotherms were determined with and without the addition of $\mathrm{NaCl}$ as a background electrolyte. For the former, ionic strength was kept constant to $10 \mathrm{mM}$ by proper addition of $1 \mathrm{M} \mathrm{NaCl}$ stock solution. In the adsorption isotherm measurements, $0.02 \mathrm{~g}$ of ground calcium silicate was mixed with $20 \mathrm{~mL}$ cesium solution with the cesium initial concentration varied from $1.3 \times 10^{-6}-3.5 \times 10^{-3} \mathrm{M}$. Both ionic strength and $\mathrm{pH}$ values were set as that of in adsorption kinetics. After the reaction/contact time, the supernatants of solution were filtered using a membrane filter with pore size of $0.45 \mu \mathrm{m}$. The filtrate was further diluted with deionized water and $10 \%$ nitric acid solution. The final concentrations were measured using inductively coupled plasma mass spectrometry (ICP-MS 7500CS, Agilent). All these experiments were conducted in triplicate.

The adsorption capacity, $q_{e}\left(\mathrm{~mol} \mathrm{~g}^{-1}\right)$, and removal percentage, $R(\%)$, were determined using equations:

$$
\begin{aligned}
& q_{e}=\left(C_{0}-C_{e}\right) \frac{V}{m} \\
& R(\%)=\frac{100\left(C_{0}-C_{e}\right)}{C_{0}}
\end{aligned}
$$

where $q_{e}$ is the adsorption capacity at equilibrium time in $\mathrm{mol} / \mathrm{g}, C_{0}$ is the initial concentration in $\mathrm{mol} / \mathrm{L}, C_{e}$ is the equilibrium concentration in mol/L, $V$ is the volume of solution in liters $(\mathrm{L}), m$ is the mass of the sorbent in grams $(\mathrm{g})$.

\subsection{FTIR sample preparation}

At first, all of the calcium silicate solid phases of the three isotherm samples were separated from the corresponding aqueous phases by filtration with a membrane filter of $0.45 \mu \mathrm{m}$ in the pore size. The obtained solid samples were then dissolved with deionized water, and further separated from the aqueous phase by centrifugation for about 10 minutes with $8000 \mathrm{rpm}$. After the centrifuge, the process was repeated from separating supernatant until it underwent centrifugation again. When completing the repetition, the separated samples were placed in a heating chamber with temperature of $90^{\circ} \mathrm{C}$ for 6 hours. The dried samples were then mixed with $\mathrm{KBr}$ using agate mortar, in which the weight ratio of samples $/ \mathrm{KBr}$ was approximately $1 / 100$. The finely ground materials were formed into pellets to be analyzed in FTIR spectrometry.

\section{Results and discussion}

\subsection{Calcium silicate insulation material prior to adsorption study}

The phase identification of calcium silicate with the ICDD (International Center for Diffraction Data) card No. 00023-0125 for xonotlite $\left(\mathrm{Ca}_{6} \mathrm{Si}_{6} \mathrm{O}_{17}(\mathrm{OH})_{2}\right)$ and card No. 00-019-1364 for tobermorite $\left(\mathrm{Ca}_{5} \mathrm{Si}_{6} \mathrm{O}_{16}(\mathrm{OH})_{2} \bullet 4 \mathrm{H}_{2} \mathrm{O}\right)$ was determined by XRD. The result shows that the ground calcium silicate insulator material is composed of predominantly xonotlite, which is in agreement with the previous study by Zheng et al (2000). Additionally, the micrograph in Fig. 3 unveils the existence of fibers and particle agglomerates, which has the $\mathrm{Ca} / \mathrm{Si}$ atomic ratio of approximately 1.00 . This ratio is important supporting evidence to validate the chemical phase of xonotlite identified by XRD since theoretically its starting material of $\mathrm{CaO} / \mathrm{SiO}$ ratio in $\mathrm{C}-\mathrm{S}-\mathrm{H}\left(\mathrm{CaO}-\mathrm{SiO}_{2}-\mathrm{H}_{2} \mathrm{O}\right)$ system should be unity (Meller et al., 2005). 


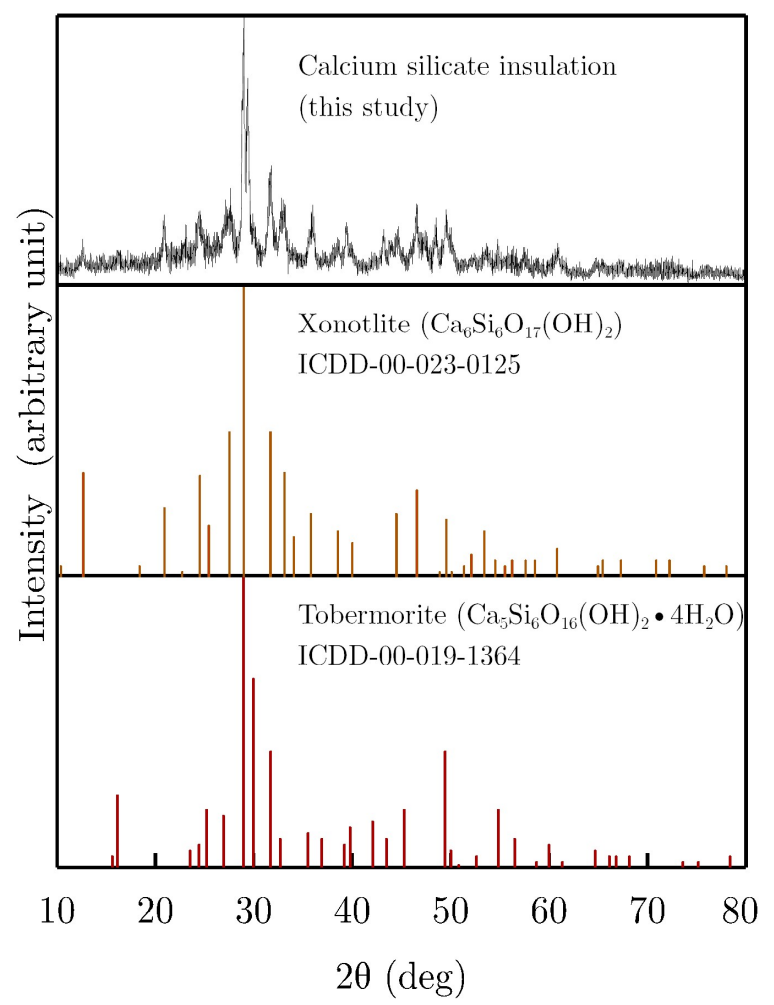

Fig. 2 XRD pattern of calcium silicate insulation

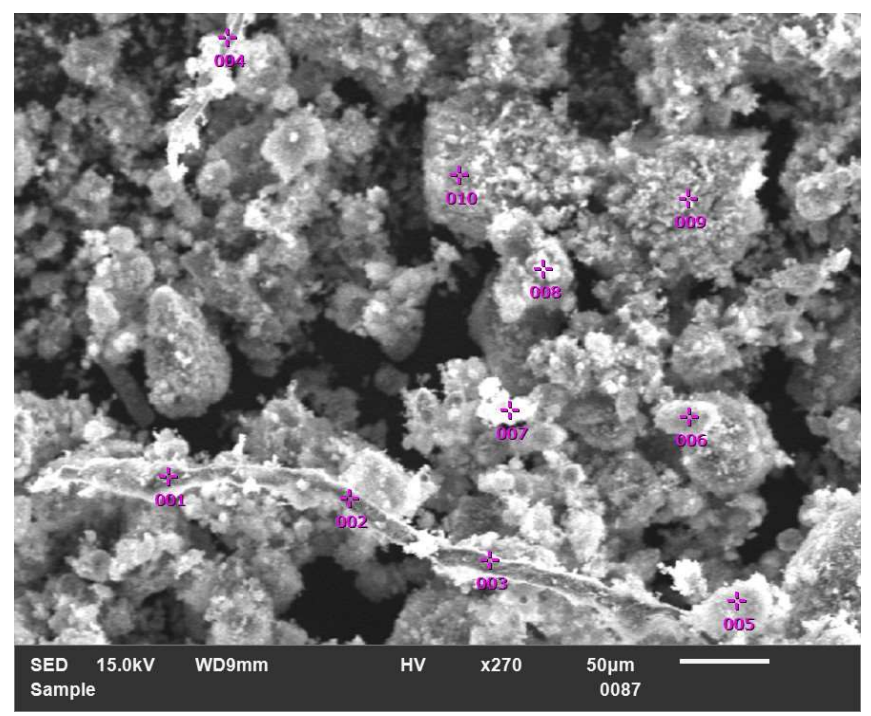

Table $1 \mathrm{Ca} / \mathrm{Si}$ atomic ratio in calcium silicate insulation

\begin{tabular}{c|c}
\hline \hline $\begin{array}{c}\text { Point location } \\
{[-]}\end{array}$ & $\begin{array}{c}\mathrm{Ca} / \mathrm{Si} \text { atomic } \\
\text { ratio [-] }\end{array}$ \\
\hline 001 & 1.04 \\
002 & 1.05 \\
003 & 1.00 \\
004 & 0.96 \\
005 & 1.01 \\
006 & 1.25 \\
007 & 1.13 \\
008 & 1.10 \\
009 & 1.25 \\
010 & 0.99 \\
\hline
\end{tabular}

Fig. 3 Secondary electron image with elemental point analysis

\subsection{Adsorption Kinetics}

The adsorption kinetics of cesium on the calcium silicate insulation was evaluated. As shown in Fig. 4(b), the adsorption of cesium reaches equilibrium within 24 hours for those samples with calcium silicate concentration of $1 \mathrm{~g} / \mathrm{L}$ and 98 hours for that of $5 \mathrm{~g} / \mathrm{L}$. Therefore, in the following equilibrium experiments (i.e. subsection 3.3), a contact time of 98 hours was selected. Adsorption mechanism of cesium on calcium silicate was investigated based on kinetics adsorption models: pseudo-first order and pseudo-second order models. The pseudo-first order rate equation and its linearized form are given in Eqs. (3) and (4), respectively. 


$$
\begin{aligned}
& \frac{d q_{t}}{d t}=K_{1}\left(q_{e}-q_{t}\right) \\
& \ln \left(q_{e}-q_{t}\right)=\ln q_{e}-K_{1} t
\end{aligned}
$$

Where $q_{t}$ and $q_{e}$ are the adsorbed amount of $\mathrm{Cs}^{+}(\mathrm{mol} / \mathrm{g})$ at time $t$ (hours) and at equilibrium, respectively; $K_{l}$ is pseudofirst order rate constant (hour ${ }^{-1}$ ). The equilibrium adsorption $q_{e}$ and rate constants $K_{l}$ are calculated by the plot of $\ln \left(q_{e}-q_{t}\right)$ vs. $t$ using Eq. (4). On the other hand, the pseudo-second order kinetics model assumes that the reaction kinetics are influenced not merely by cesium concentration (i.e. as in the pseudo-first order model), but also by the active sites on adsorbent. The model and its linearized form are given in Eqs. (5) and (6) as the following:

$$
\begin{aligned}
& \frac{d q_{t}}{d t}=K_{2}\left(q_{e}-q_{t}\right)^{2} \\
& \frac{t}{q_{t}}=\frac{1}{K_{2} q_{e}^{2}}+\frac{t}{q_{e}}
\end{aligned}
$$

$K_{2}$ is pseudo-second order rate constant ( $\mathrm{g} / \mathrm{mol}$ hour). The equilibrium adsorption $q_{e}$ and rate constants $K_{2}$ are determined by plotting $t / q_{t} v s$. $t$ using Eq. (6). Two criteria were considered as the basis to determine the most likely adsorption mechanism: (1) relative difference between the adsorbed amount of $\mathrm{Cs}^{+}$at equilibrium obtained by the experiment and the kinetics model $\left(q_{e, \text { experiment }}\right.$ and $\left.q_{e, \text { model }}\right)$; (2) the correlation coefficients of the fitting $\left(\mathrm{R}^{2}\right)$. The favorable condition is least difference between $q_{e, \text { experiment }}$ and $q_{e, \text { model }}$, and $\mathrm{R}^{2}$ close to unity. The obtained parameters of the pseudo-first order and pseudo-second order models are listed on Table 2. Based on our experimental data, the adsorption of cesium on calcium silicate was better fitted to the pseudo-second order models, which indicated that $\mathrm{Cs}^{+}$was chemisorbed and the adsorption rate of calcium silicate insulator material depended on the active sites rather than $\mathrm{Cs}^{+}$concentration in the solution (Lee et al., 2018). The subsequent isotherm adsorption and also FTIR analysis in subsection 3.4 were intended as the supporting proof of such adsorption process.

The cesium removal percentage by calcium silicate with a different crystal phase, wollastonite, showed significant difference to our study. This type of calcium silicate has lower removal percentage even comparing with $1 \mathrm{~g} / \mathrm{L}$ of xonotlite-type calcium silicate (10 times less adsorbent concentration). Moreover, in terms of equilibrium, it had been achieved within 0.5 to 1 hours of contact time while our kinetics study showed equilibrium was achieved within 24 hours (i.e. those of $1 \mathrm{~g} / \mathrm{L}$ adsorbent concentration). These conditions explicitly infer the inapplicability of extending cesium adsorption behavior on wollastonite-type calcium silicate to approach such a phenomenon in calcium silicate insulation of the Fukushima Daiichi NPS case.

Table 2 Pseudo-first order and pseudo-second order parameters for cesium adsorption on calcium silicate

\begin{tabular}{l|l|l|l|l|l|l|l|l|l|l}
\hline & \multicolumn{3}{|c|}{ Pseudo-first order kinetics model } & \multicolumn{3}{c}{ Pseudo-second order kinetics model } \\
\cline { 2 - 9 } Sample & $\begin{array}{l}\mathrm{K}_{1} \\
\left(\mathrm{~h}^{-1}\right) \\
\times 10^{-2}\end{array}$ & $\begin{array}{l}\mathrm{q}_{\mathrm{e}} \\
\text { experiment } \\
(\mathrm{mol} / \mathrm{g}) \\
\times 10^{-5}\end{array}$ & $\begin{array}{l}\mathrm{q}_{\mathrm{e} \text { model }} \\
(\mathrm{mol} / \mathrm{g}) \\
\times 10^{-5}\end{array}$ & $\begin{array}{l}\text { Rel. } \\
\text { diff. } \\
(\%)\end{array}$ & $\mathrm{R}^{2}$ & $\begin{array}{l}\mathrm{K}_{2} \\
(\mathrm{~g} / \mathrm{mol} / \mathrm{h}) \\
\times 10^{4}\end{array}$ & $\begin{array}{l}\mathrm{q}_{\mathrm{e}} \\
\text { experiment } \\
(\mathrm{mol} / \mathrm{g}) \\
\times 10^{-5}\end{array}$ & $\begin{array}{l}\mathrm{q}_{\mathrm{e} \text { model }} \\
(\mathrm{mol} / \mathrm{g}) \\
\times 10^{-5}\end{array}$ & $\begin{array}{l}\text { Rel. } \\
\text { diff. } \\
(\%)\end{array}$ & $\mathrm{R}^{2}$ \\
\hline $\begin{array}{l}0.02 \mathrm{~g} ; \\
1.0 \times 10^{-4} \mathrm{~mol} / \mathrm{L} \\
0.1 \mathrm{~g} ; \\
1.0 \times 10^{-4} \mathrm{~mol} / \mathrm{L}\end{array}$ & 9.42 & 2.30 & 1.04 & 54.6 & 0.966 & 3.53 & 2.30 & 2.33 & 0.990 & 0.999 \\
$\begin{array}{l}0.02 \mathrm{~g} ; \\
1.0 \times 10^{-5} \mathrm{~mol} / \mathrm{L}\end{array}$ & 1.66 & 0.300 & 0.140 & 52.2 & 0.626 & 8.18 & 0.300 & 0.310 & 1.25 & 0.983 \\
\hline
\end{tabular}




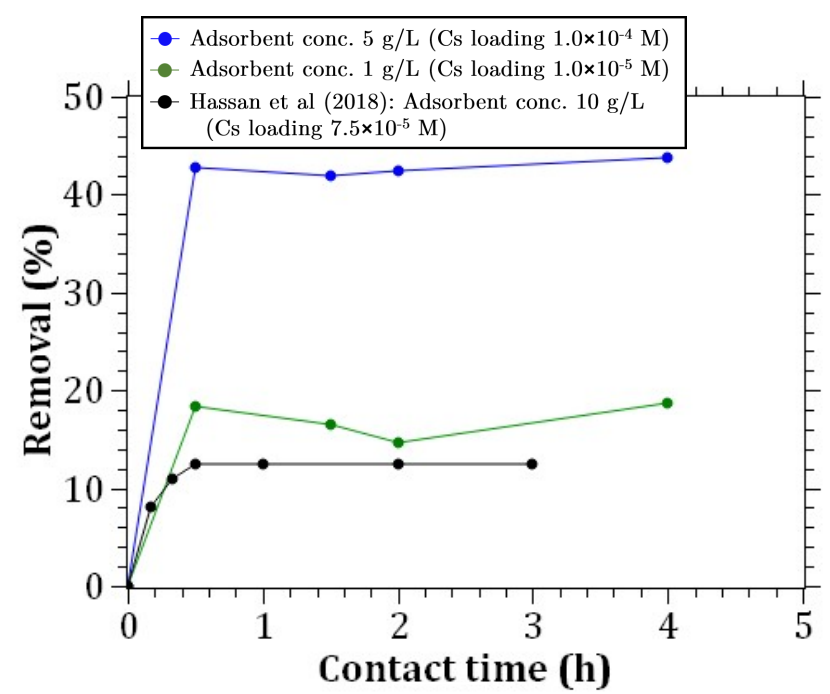

(a)

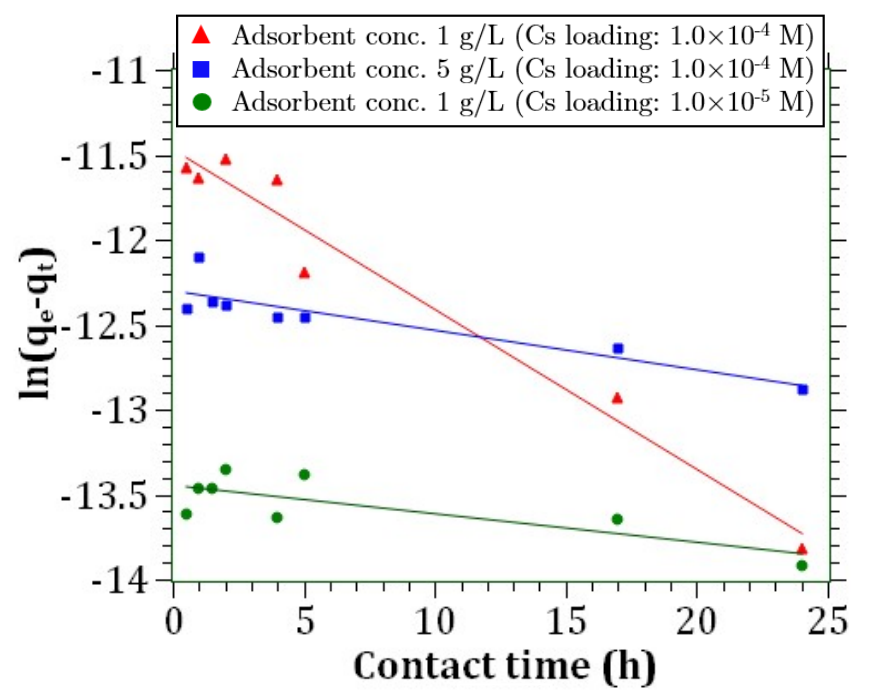

(c)

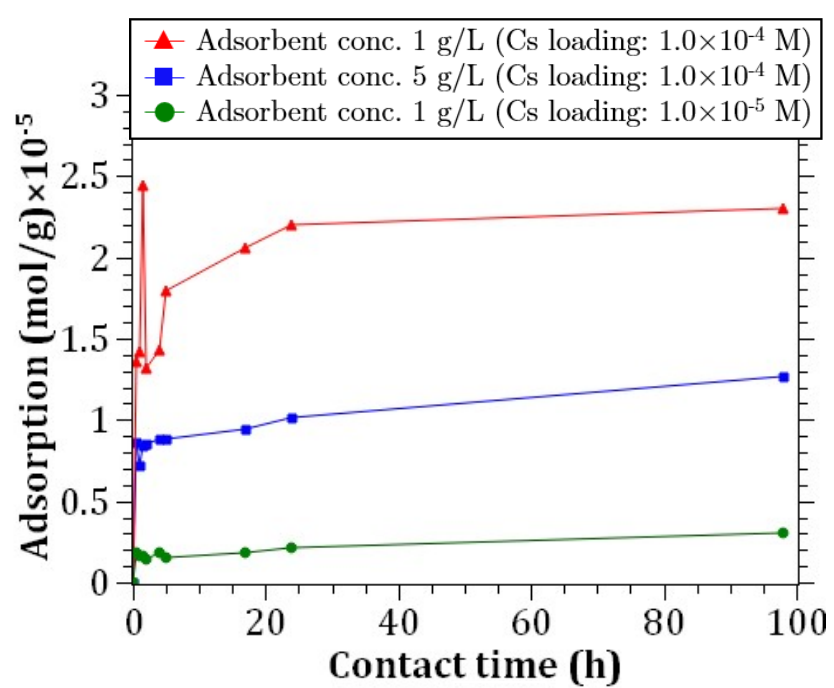

(b)

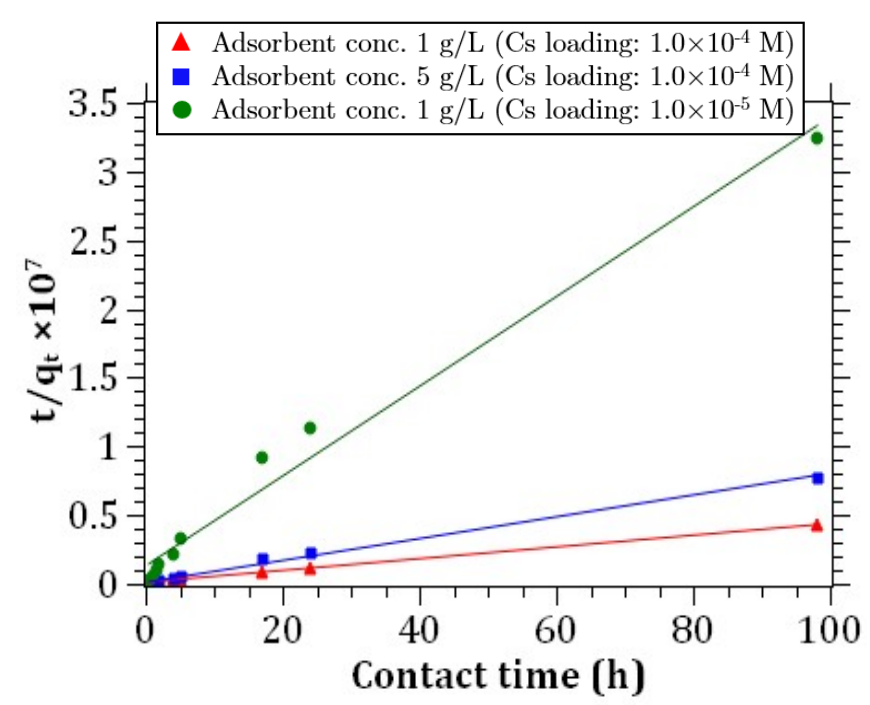

(d)

Fig. 4 (a) Comparison on cesium removal from aqueous solution by xonotlite-type calcium silicate in this study and wollastonite-type calcium silicate in Hassan et al (2018); (b) The effect of contact time on cesium adsorption of calcium silicate; (c) Pseudo-first order kinetics model; (d) Pseudo-second order kinetics model. (Initial concentrations of Cs: $1.0 \times 10^{-5}$ and $1.0 \times 10^{-4} \mathrm{~mol} / \mathrm{L}$; adsorbent concentration: $1 \mathrm{~g} / \mathrm{L}$ and $5 \mathrm{~g} / \mathrm{L}$, temperature: $25^{\circ} \mathrm{C}$, maximum contact time: 98 hours)

\subsection{Adsorption isotherm}

The adsorption isotherm of cesium to the calcium silicate was investigated in order to evaluate the performance-in addition to validate findings in adsorption kinetics-with regard to the maximum adsorption capacity $\left(q_{m}\right)$. Its corresponding value represents the theoretical maximum capacity or adsorbent ability to adsorb cesium at saturation conditions. The models that had been implemented in our adsorption isotherm experimental data including the twoparameter model: Langmuir (Long et al., 2013; Xia et al., 2018), and three-parameter model: modified-BrunauerEmmett-Teller (BET) (Ebadi et al., 2009). The approach for the solution in the two-parameter model was done using linear regression while for the three-parameter model using non-linear regression. The Langmuir and modified-BET models are expressed in Eq. (7) and (8), respectively. 


$$
\begin{aligned}
& q_{e}=q_{m} \frac{{ }_{L m}{ }^{C} e_{e}}{1+K_{L m}{ }^{C}{ }_{e}} \\
& q_{e}=q_{m} \frac{K_{S} C_{e}}{\left(1-K_{L} C_{e}\right)\left(1-K_{L} C_{e}+K_{S} C_{e}\right)}
\end{aligned}
$$

where $K_{L m}$ is Langmuir adsorption isotherm constant in L/mol, $K_{S}$ is the equilibrium constant of adsorption for BET firstsite in $\mathrm{L} / \mathrm{mol}, K_{L}$ is the equilibrium constant of adsorption for upper sites in $\mathrm{L} / \mathrm{mol}$, and $q_{m}$ adsorption capacity of adsorbent in $\mathrm{mol} / \mathrm{g}$, respectively. The optimized parameters of those models are given in Table 3.

Table 3 Estimated parameters of adsorption isotherm models

\begin{tabular}{c|c|c|c|c|c}
\hline \hline \multirow{2}{*}{ Sample } & \multicolumn{2}{|c|}{$\begin{array}{c}\text { Langmuir isotherm } \\
\text { model }\end{array}$} & \multicolumn{3}{|c}{$\begin{array}{c}\text { Modified BET isotherm } \\
\text { model }\end{array}$} \\
\cline { 2 - 6 } & $\begin{array}{c}\mathrm{K}_{\mathrm{Lm}} \\
(\mathrm{L} / \mathrm{mol})\end{array}$ & $\begin{array}{c}\mathrm{q}_{\mathrm{m}} \\
(\mathrm{mol} / \mathrm{g})\end{array}$ & $\begin{array}{c}\mathrm{K}_{\mathrm{S}} \\
(\mathrm{L} / \mathrm{mol})\end{array}$ & $\begin{array}{c}\mathrm{K}_{\mathrm{L}} \\
(\mathrm{L} / \mathrm{mol})\end{array}$ & $\begin{array}{c}\mathrm{q}_{\mathrm{m}} \\
(\mathrm{mol} / \mathrm{g})\end{array}$ \\
\hline Calcium silicate & 8.9 & 0.047 & 11 & 0.38 & 0.061 \\
\hline
\end{tabular}

We have seen from the adsorption kinetics analysis that $\mathrm{Cs}^{+}$was chemisorbed to sorption sites of the calcium silicate insulator material. The nature of the interaction was further analyzed through the two isotherms with and without the presence of competing ion $\mathrm{Na}^{+}$. If such inferred dependency was incorrect, then there should be no effect before and after introducing $\mathrm{Na}^{+}$to the solution and only one isotherm model is necessary to explain them. In fact, as presented in Fig. 5 , the Langmuir model was only applicable in our study with $\mathrm{Na}^{+}$while modified-BET only for that without $\mathrm{Na}^{+}$because each model represented different phenomenon as sorbate concentration increased. Without $\mathrm{Na}^{+}$, three distinctive processes became apparent as a function of $\mathrm{Cs}^{+}$concentration: the dashed red line represents the dominant adsorption process is surface complexation; the solid red line represents surface site saturation; the dash-dot red line represents surface precipitation (Farley et. al., 1985; Lützenkirchen and Behra, 1995). On the other hand, when $\mathrm{Na}^{+}$was introduced to the solution, the selectivity adsorption of sorbent (calcium silicate) occurred between $\mathrm{Na}^{+}$and $\mathrm{Cs}^{+}$(Zheng et al., 2017; Alamudy and Cho, 2018; Xia et al., 2018) which in turn could decrease the activity of $\mathrm{Cs}^{+}$and available adsorption sites. This can be deduced on the results where surface precipitation was hindered, and the adsorption capacity was reduced from $0.061 \mathrm{mmol} / \mathrm{g}$ to $0.047 \mathrm{mmol} / \mathrm{g}$. These effects could be explained by the fact that $\mathrm{Na}^{+}$competed for the sorption with $\mathrm{Cs}^{+}$or screened the negative electrostatic potential of the sorbent and diminished the favorable interaction with $\mathrm{Cs}^{+}$.

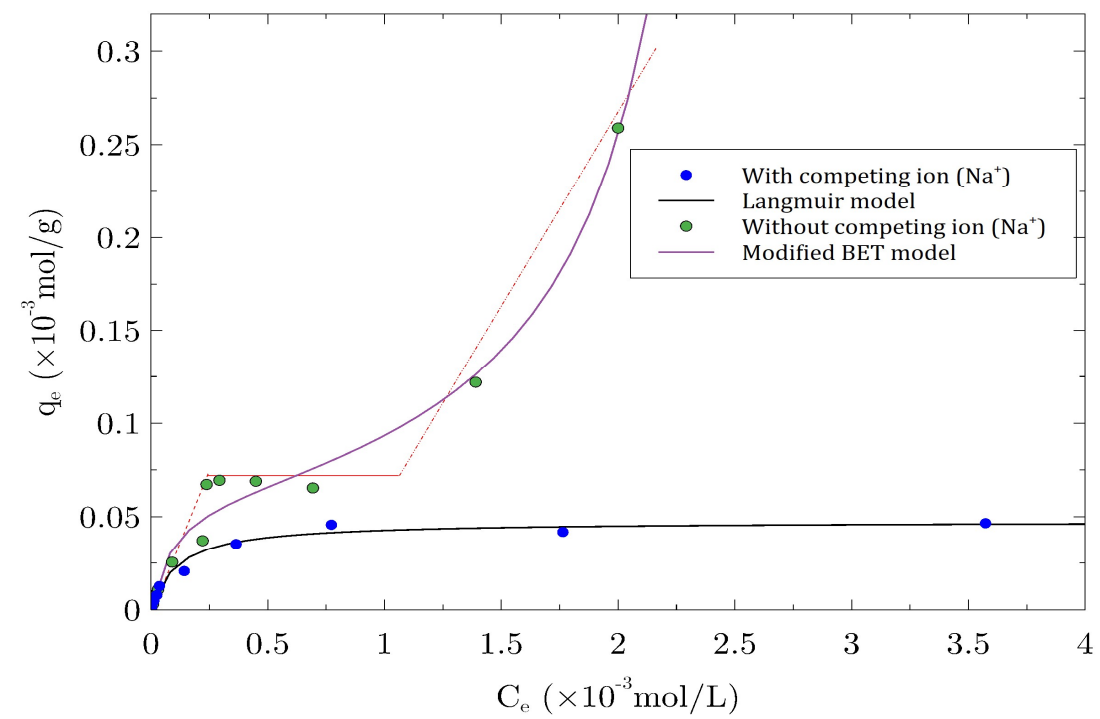

Fig. 5 Adsorption isotherm results of calcium silicate as function of cesium concentration under the effect of competing ion in the aqueous solution (Cs loading: $1.3 \times 10^{-6}-3.5 \times 10^{-3} \mathrm{M}$; Na loading: $0.01 \mathrm{M}$; adsorbent concentration: $1 \mathrm{~g} / \mathrm{L}$; temperature: $25^{\circ} \mathrm{C}$, contact time: 98 hours). 


\subsection{FTIR analysis}

The procedure that had been performed in this analysis was arranged in accordance to rule out the possibility of cesium physically adsorbed on calcium silicate. The samples from the adsorption isotherm experiments without $\mathrm{Na}^{+}$were used so that we could obtain the nature of adsorption in this material. Three samples were selected based on the observed phenomenon (i.e., surface complexation, surface site saturation, and surface precipitation) and one sample without Cs intake. Here, after completing the procedure (as described in subsection 2.4), only the higher binding energy between sorbate and sorbent would withstand which is chemisorption. Therefore, the change of respective vibrational modes in FTIR analysis after those procedures will represent such a sorption process.

The nature of vibrational mode in this calcium silicate insulator material was the characteristic of its predominant chemical compound, xonotlite. There are three groups of vibration bands appear: the first group is due to $\mathrm{CO}^{-3}$ vibration, the second group is due to bending and stretching vibrations of water molecules and $\mathrm{O}-\mathrm{H}$ groups, and the third group is silicate tetrahedral vibrations (Mostafa et al., 2009). Among these groups of the bands, we observed the shift of vibrational mode occurred by the interaction with $\mathrm{Cs}^{+}$on the silicate tetrahedral second intense absorption with the wavenumber of 550-400 $\mathrm{cm}^{-1}$. This is the O-Si-O deformation or bending mode (Yu et al., 1999; Mostafa et al., 2009; Hartmann et al., 2015). Initially, in the sample without $\mathrm{Cs}$ loading, this mode has a sharp peak at $462 \mathrm{~cm}^{-1}$ and a shoulder at $456 \mathrm{~cm}^{-1}$ (black line), in which the absorbance intensity difference between them is about $60 \%$. Upon Cs loading, the peak and shoulder intensity behaved differently. At the Cs loading of $4.0 \times 10^{-5} \mathrm{M}$ (condition of surface complexation) the peak intensity was reduced and slightly shifted to $463 \mathrm{~cm}^{-1}$ while the shoulder intensity increased. This is because the bending or deformation vibrations of $\mathrm{O}-\mathrm{Si}-\mathrm{O}$ are inhibited by $\mathrm{Cs}^{+}$occupancy on the active sites which in turn yielding lower intensity than that of without $\mathrm{Cs}$ loading. As the Cs loading attained saturation on $3.1 \times 10^{-4} \mathrm{M}$ which completely occupied all the active sites, the peak on $463 \mathrm{~cm}^{-1}$ was undetectable and only the previous shoulder remained on $456 \mathrm{~cm}^{-1}$. At last, when the Cs loading increased to $2.3 \times 10^{-3} \mathrm{M}$ (the condition of surface precipitation), the shoulder turned as the new peak at $458 \mathrm{~cm}^{-1}$. The new observed peak at $458 \mathrm{~cm}^{-1}$ has signified the formation of a surface phase whose composition varies between that of the original solid and a pure precipitate of sorbate (Farley et al, 1985). Indeed, the formation would involve coordination between silicate and Cs but to some extent the exact compound and how it occurs couldn't be

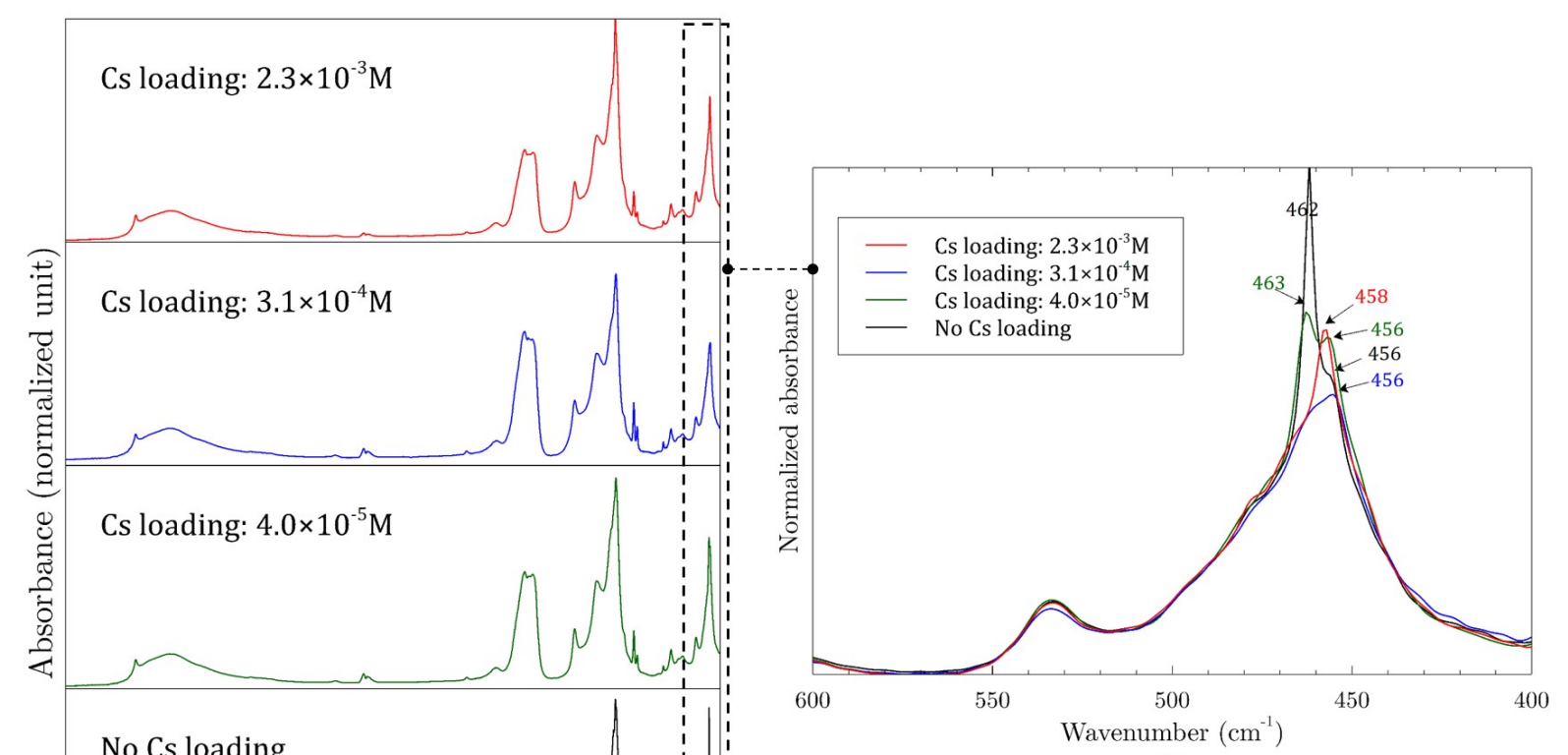

(b) 
unveiled by infrared spectroscopy. Thus, some proper underlying investigation measures are required in the future, for instance unveiling local structure of materials by extended X-ray absorption fine structure (EXAFS) which has been demonstrated by Schlegel et al (2004) when investigating Eu(III) uptake on calcium silicate hydrate (i.e., in which one of the samples was $\mathrm{Ca} / \mathrm{Si}=1.0$ ). They have interpreted the results that the coordination of Eu(III) occurred by the replacement of $\mathrm{Ca}^{2+}$ in $\mathrm{Ca}$ layer and the interlayer leading to the formation of $\mathrm{C}-\mathrm{S}-\mathrm{H}$-like solid phase (surface precipitate).

\section{Conclusions}

Room-temperature adsorption behavior of cesium on a calcium silicate insulation material predominantly composed of xonotlite $\mathrm{Ca}_{6} \mathrm{Si}_{6} \mathrm{O}_{17}(\mathrm{OH})_{2}$ ) was studied by analyzing the adsorption kinetics, isotherm, and the infrared spectroscopy. The adsorption kinetics showed that the adsorption process of cesium followed the pseudo-second order reaction model that highly indicated chemisorption of cesium. Equilibrium of adsorption was achieved within 24 hours for the low adsorbent concentration $(1 \mathrm{~g} / \mathrm{L})$ and 98 hours for the high concentration $(5 \mathrm{~g} / \mathrm{L})$. To further unveil the sorption process, the adsorption isotherms were obtained with and without the competing $\mathrm{Na}^{+}$ion in aqueous solutions. The data were represented well with the Langmuir isotherm model in the presence of $\mathrm{Na}^{+}$while the modified Brunauer-Emmett-Teller isotherm model fitted well to that without $\mathrm{Na}^{+}$. This clearly showed that the adsorption process was altered where surface sites became limited or favorable interaction was screened by $\mathrm{Na}^{+}$, and the formation of surface precipitates were hindered. The FTIR spectroscopy provided supporting evidence for such sorption that the vibrational peak of $\mathrm{O}-\mathrm{Si}-\mathrm{O}$ deformation or bending mode was attenuated and shifted from 462 to $458 \mathrm{~cm}^{-1}$ as a result of the formation of surface complexes and precipitates.

The findings in this study have revealed that at room-temperature condition, cesium could be retained on calcium silicate insulation material. Nevertheless, if we reflect on the actual case of accident progression, the room-temperature condition could be achieved in the late phase after ex-vessel or in-vessel cooling. Meaning that our results could solely answer the possibility of cesium retention after such condition prevailed. In the future, Authors aim to proceed with the investigation on high-temperature interaction - as what Authors have indicated in the Introduction part — which expected to elucidate the early phase of calcium silicate deformation due to exposure of steam mixed with cesium and at last the cesium being retained on the material. The integration of present and future studies is imperative to construct a comprehensive answer about high dose rate reading on the pedestal of Fukushima Daiichi nuclear power station unit 2.

\section{Acknowledgment}

The authors would like to thank Dr. Qian Zhou of Nuclear Professional School (The University of Tokyo) for the assistance of laser diffraction size analyzer. The members of Development Group of Advanced LWR Technology-JAEA are appreciated for the collaboration with the use of XRD.

\section{References}

Alamudy, H. A. and Cho, K., Selective adsorption of cesium from an aqueous solution by a montmorillonite-prussian blue hybrid, Chemical Engineering Journal, Vol.349 (2018), pp.595-602.

Chang, S. J., Furuya, H., Fujii, T. and Idemitsu, K., Corrosion of austenitic stainless steel in steam containing cesium hydroxide, Journal of Nuclear Science and Technology, Vol.29, No.8 (1992), pp.753-761.

Di Lemma, F. G., Nakajima, K., Yamashita, S. and Osaka, M., Surface analyses of cesium hydroxide chemisorbed onto type 304 stainless steel, Nuclear Engineering and Design, Vol.305 (2016), 414-420.

Ebadi, A., Mohammadzadeh. J. S. S. and Khudiev, A., What is the correct form of BET isotherm for modeling liquid phase adsorption?, Adsorption, Vol.15 (2009), pp.65-73.

Farley, K. J., Dzombak, D. A., and Morel, F. M. M., A surface precipitation model for the sorption of cations on metal oxides. Journal of Colloid and Interface Science, Vol.106, No.1 (1985), pp.226-242.

Gaona, X., Dahn, R., Tits, J., Scheinost, A. C. and Wieland, E., Uptake of Np(IV) by C-S-H phases and cement paste: an EXAFS study, Environmental Science and Technology, Vol.45, No.20 (2011), pp.8765-71. 
Hartmann, A., Schulenberg, D. and Buhl, J. C., Investigation of the transition reaction of tobermorite to xonotlite under influence of additives, Advances in Chemical Engineering and Science, Vol.05 (2015), 197-214.

Hassan, H. S., Kenawy, S. H., El-Bassyouni, G. T., Hamzawy, E. M. A. and Hassan, R. S., Sorption behavior of cesium and europium radionuclides onto nano-sized calcium silicate, Particulate Science and Technology (2018).

Haste, T., Payot, F. and Bottomley, P. D. W., Transport and deposition in the Phébus FP circuit, Annals of Nuclear Energy, Vol.61 (2013). pp.102-121.

Kalilainen, J., Kärkelä, T., Zilliacus, R., Tapper, U., Auvinen, A. and Jokiniemi, J., Chemical reactions of fission product deposits and iodine transport in primary circuit conditions, Nuclear Engineering and Design, Vol.267 (2014), pp.140-147.

Lee, I., Kim, S. H., Rethinasabapathy, M., Haldorai, Y., Lee, G. W., Choe, S. R., Kang, S. C., Han, Y. K., Roh, C., Cho, W. S. and Huh, Y. S., Porous 3D Prussian blue/cellulose aerogel as a decorporation agent for removal of ingested cesium from the gastrointestinal tract, Scientific Reports, Vol.8, No.4540 (2018).

Leite, F. H. G., Almeida, T. F., Faria, R. T. and Holanda, J. N. F., Synthesis and characterization of calcium silicate insulating material using avian eggshell waste, Ceramic International, Vol.43 (2017), pp.4674-4679.

Long, H., Wu, P. and Zhu, N., Evaluation of $\mathrm{Cs}^{+}$removal from aqueous solution by adsorption on ethylamine-modified montmorillonite, Chemical Engineering Journal, Vol.225 (2013), pp.237-244.

Lützenkirchen, J. and Behra, P., On the surface precipitation model for cation sorption at the (hydr)oxide water interface, Aquatic Geochemistry, Vol.1, No.4 (1995), pp.375-397.

Meller, N., Hall, C. and Phipps, J. S., A new phase diagram for the $\mathrm{CaO}-\mathrm{Al}_{2} \mathrm{O}_{3}-\mathrm{SiO}_{2}-\mathrm{H}_{2} \mathrm{O}$ hydroceramic system at $200^{\circ} \mathrm{C}$, Materials Research Bulletin, Vol.40 (2005), pp.715-723.

Mostafa, N. Y., Shaltout, A. A., Omar, H. and Abo-El-Enein, S. A., Hydrothermal synthesis and characterization of aluminium and sulfate substituted $1.1 \mathrm{~nm}$ tobermorites, Journal of Alloys and Compounds, Vol.467 (2009), pp.332-337.

Nuclear and Industrial Safety Agency, Report on emergency core cooling system strainer and containment vessel recirculation sump screen blocking event and status of measures on boiling water nuclear power plant (2006). Japan: Nuclear and Industrial Safety Agency (NISA), $44^{\text {th }}$ Nuclear Safety Commission, Report material no. 2 (in Japanese).

Schlegel, M. L., Pointeau, I., Coreau, N. and Reiller, P., Mechanism of europium retention by calcium silicate hydrates: an EXAFS study, Environmental Science and Technology, Vol.38, No.16 (2004), pp.4423-4431.

Steve, L. P., Kowalski, M., Pšenička , M., Klinkenberg, M., Rohmen, S., Bosbach, D. and G. Deissmann., Uptake of ${ }^{226} \mathrm{Ra}$ in cementitious systems: a complementary solution chemistry and atomistic simulation study, Applied Geochemistry, Vol.96 (2018), pp.204-216.

Tits, J., Wieland, E., Muller, C. J., Landesman, C. and Bradbury, M. H., Strontium binding by calcium silicate hydrates, Journal Colloid and Interface Science, Vol.300, No.1 (2006), pp.78-87.

Tits, J., Fujita, T., Harfouche, M., Dahn, R., Tsukamoto, M. and Wieland, E., Radionuclide uptake by calcium silicate hydrates: Case studies with Th(IV) and U(VI). Switzerland: Paul Scherrer Institut (2014).

Tokyo Electric Power Company (TEPCO), Internal exploration of the unit 2 primary containment vessel (PCV): reevaluation of dose rate estimate, (2017).

Tokyo Electric Power Company (TEPCO), Progress report No. 5: Evaluation of the situation of cores and containment vessels of Fukushima Daiichi nuclear power station units-1 to 3 and examination into unsolved issues in the accident progression, (2017).

Xia, M., Zheng, X., Du, M., Wang, Y., Ding, A. and Dou, J., The adsorption of $\mathrm{Cs}^{+}$from wastewater using lithiummodified montmorillonite caged in calcium alginate beads, Chemosphere, Vol.203 (2018), pp.271-280.

Yu, P., Kirkpatrick, R. J., McMillan, P. F., Poe, B., Cong, X., Structure of calcium silicate hydrate (C-S-H): Near-, mid-, and far-infrared spectroscopy, Journal of the American Ceramic Society, Vol.82, No.3 (1999), 742-748.

Zheng, Q. and Wang, W., Calcium silicate based high efficiency thermal insulation, British Ceramic Transactions, Vol.99, No.4 (2000), pp.187-190.

Zheng, X., Dou, J., Yuan, J., Qin, W., Hong, X., Ding, A., Removal of $\mathrm{Cs}^{+}$from water and soil by ammonium-pillared montmorillonite/Fe3O4 composite, Journal of Environmental Science, Vol.56 (2017), pp.12-24. 